\title{
Da orientaçáo profissional à inserção laboral de usuários de serviços de saúde mental em empreendimentos econômicos solidários ${ }^{1}$
}

\author{
Letícia Gomes da Silva ${ }^{\mathrm{a}}$, Ana Lucia Cortegoso ${ }^{\mathrm{b}, \mathrm{c}}$, Isabela Aparecida de Oliveira Lussid ${ }^{\mathrm{de}}$ \\ ${ }^{a}$ Curso de Psicologia, Universidade Federal de São Carlos - UFSCar, São Carlos, SP, Brasil

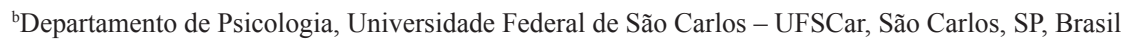 \\ 'Programa de Pós-graduação em Educação Especial, Universidade Federal de São Carlos - UFSCar, \\ São Carlos, SP, Brasil \\ ${ }^{\mathrm{d}}$ Departamento de Terapia Ocupacional, Universidade Federal de São Carlos - UFSCar, São Carlos, SP, Brasil \\ ePrograma de Pós-graduação em Terapia Ocupacional, Universidade Federal de São Carlos - UFSCar, \\ São Carlos, SP, Brasil
}

\begin{abstract}
Resumo: Com o movimento da reforma psiquiátrica, refletir sobre a reabilitação de usuários de serviços de saúde mental na sociedade se tornou essencial. Visando à inclusão de usuários de serviços de saúde mental em empreendimentos econômicos solidários e buscando maneiras de favorecer essa inclusão, a implementação de processos de orientação profissional foi tomada como ferramenta potencial. O presente projeto de pesquisa teve como objetivo investigar o potencial do processo de orientação profissional como estratégia para a inserção de pessoas em empreendimentos econômicos solidários. Para coleta de dados foram realizadas entrevistas semiestruturadas com cinco participantes, sendo eles: dois usuários de serviços de saúde mental integrantes do programa de orientação profissional ocorrido em 2010, o técnico executivo responsável pelo acompanhamento do empreendimento econômico solidário onde houve a inserção desses usuários e dois cooperados não usuários de serviços de saúde mental desse mesmo empreendimento. Foi realizado também um exame das atas dos encontros dedicados à orientação profissional e os dados provenientes desse exame foram utilizados como complementação dos dados obtidos nas entrevistas. O tratamento dos dados foi subsidiado pelos pressupostos teóricos da Economia Solidária, da orientação profissional e da desinstitucionalização. Os resultados convergem na direção da orientação profissional como facilitadora da inserção dos usuários de serviços de saúde mental no empreendimento econômico solidário e embora algumas limitações tenham sido encontradas, apontando a necessidade de realizar novos estudos, os resultados permitem concluir que a orientação profissional é uma alternativa viável para facilitar a inclusão laboral dessa população.
\end{abstract}

Palavras-chave: Saúde Mental, Orientação Profissional, Economia Solidária.

\section{From career guidance to the labor insertion of users of mental health services in solidarity economy enterprises}

\begin{abstract}
With the psychiatric reform movement, reflecting on the rehabilitation of users of mental health services in society has become essential. Aiming to include users of mental health services in solidarity economy enterprises and seeking ways to promote this inclusion, career guidance was taken as a potential tool. This research project aimed to investigate the potential of the process of career guidance as a strategy for the inclusion of these users in solidary economy enterprises. Semi-structured interviews were used for data collection. The participants were two users of mental health services that were members of the career orientation program held in 2010, the technician responsible for the solidarity economy enterprise, and two non-users of mental health services. We also carried out
\end{abstract}

Autor para correspondência: Letícia Gomes da Silva, Departamento de Psicologia, Centro de Educação e Ciências Humanas, Universidade Federal de São Carlos, Rodovia Washington Luiz, km 235, CP 676, CEP 13565-905, São Carlos, SP, Brasil, e-mail: btleticia@ hotmail.com Recebido em 6/6/2013; Revisão em 17/3/2014; Aceito em 23/4/2014. 
an analysis of the minutes of the career guidance meetings, and the data from this analysis were used to complement the data obtained in the interviews. Data analysis was based on the theoretical assumptions of solidarity economics and guidance for vocation and deinstitutionalization. The results converge toward career guidance as a facilitator of the insertion of users of mental health services in solidarity economy enterprises. Although some limitations have been found indicating the need to conduct new studies, results suggest that career guidance is a viable alternative to facilitate the inclusion of this population.

Keywords: Mental Health, Career Guidance, Solidarity Economics.

\section{Introdução}

As pessoas com transtorno mental, assim como mendigos, criminosos e pessoas com doenças venéreas, ou seja, aqueles considerados pela maioria como desajustados, foram postos à margem da sociedade de forma que o enclausuramento em instituiçóes como prisôes, casas de correção e hospitais tornaram-se as únicas opçôes ofertadas a essa população. Tais instituições constituíam verdadeiros reservatórios de desviantes das normas e, portanto, representantes do que era indesejável socialmente (NASCIMENTO, 1991; BASAGLIA, 1985).

Atualmente - sendo a substituição progressiva dos manicômios por outras práticas terapêuticas e o cuidado em preservar a cidadania do portador de transtorno mental objetivos propostos pela reforma psiquiátrica -, o fenômeno da loucura vem sendo objeto de discussão não só entre os profissionais de saúde, mas também em toda a sociedade (GONÇALVES; SENA, 2001).

Com o movimento da reforma psiquiátrica, ampliaram-se os debates sobre as formas como as pessoas com transtorno mental eram vistas e tratadas e lidar com a reabilitaçáo dessas pessoas na sociedade se tornou essencial. Reabilitar, nesse contexto, significa garantir o acesso aos direitos de cidadania, ao exercício progressivo desses direitos, a capacidade de promovê-los e reconhecê-los, sejam direitos de ordem política, social ou jurídica (ROTELLI, 1994).

A literatura aponta o processo de reabilitação como meio para a reconstrução do exercício pleno de cidadania e aumento da capacidade contratual dos portadores de transtorno mental, as quais devem ocorrer nos cenários do habitat, da rede social e do trabalho com valor social (SARACENO, 1996, 2001; PITTA, 1996). Nesse processo de reabilitaçáo, a conquista da autonomia pessoal, a instrução, a formação profissional, a capacidade de exercer uma funçáo social - manifestando opiniōes e sendo ouvindo - são os principais objetivos a serem alcançados, mas o que de fato deve ser reabilitativo é o meio pelos quais esses objetivos são alcançados.
Em suma, no processo de reabilitação psicossocial é relevante considerar que as relaçóes interpessoais são de extrema importância na modificaçáo concreta da realidade do sujeito, assim como o uso de bens e serviços, a presença participativa nos locais que ele habita e o trabalho que, dentre outros direitos, assume um papel de destaque, já que estrutura a existência humana e social, permitindo a inserção social por meio da produçáo ou prestação de um serviço à sociedade (ROTELLI, 1994).

A história da produção e reprodução do ser social só se efetiva pelo trabalho, pois esse é um importante constituinte da realização do ser social, condição para sua existência, sendo esse o ponto de partida para a sua humanização (MARX, 1984 apud CATÃO; TRINDADE, 1998). O trabalho está presente na história da Psiquiatria mesmo antes das instituições psiquiátricas, sendo inicialmente utilizado como forma de combater a pobreza e a ociosidade e, posteriormente, considerado recurso terapêutico. Porém, o objetivo terapêutico do trabalho era corrigir a forma de agir dos pacientes considerada fora dos padróes da normalidade aceitos socialmente, controlar, punir, premiar os que seguiam as regras institucionais e reduzir os gastos da instituição (NASCIMENTO, 1991).

A partir do movimento de reforma psiquiátrica, a questão do trabalho como meio terapêutico também foi revista; surgiu a discussão sobre o direito ao trabalho entendido por rentável, como ferramenta que promove autoafirmação, gera possibilidade de troca e rede, diminui o estigma ligado à saúde metal e, principalmente, é realizado fora dos muros dos manicômios (ROTELLI, 2000 apud LUSSI, 2009).

Trabalhar é uma importante via de inclusão social; no entanto, embora o homem moderno busque cada vez mais formas de se incluir socialmente por meio do trabalho, esse mesmo homem desconsidera o fato de esse trabalho não ser tão disponível nem tão flexível para suportar as diferentes demandas individuais e coletivas que a sociedade moderna impóe (SILVA; OLIVEIRA; BERTANI, 2007).

Fortemente ligada ao modelo capitalista, a exclusão é o destino que o capitalismo oferece para a classe 
trabalhadora já socialmente excluída, aquela julgada como incapaz, como as pessoas com transtorno mental; a essa parcela da população a lógica capitalista deixa apenas a assistência e a invalidação social subjetiva como destino. Sendo assim, pessoas com transtorno mental se tornam duplamente excluídas: são excluídas pela doença e pelo mercado de trabalho (SILVA; OLIVEIRA; BERTANI, 2007). O trabalho para pessoas com transtorno mental não pode, entáo, restringir-se ao simples desenvolver de tarefas, que acabam por mantê-los na restrição do campo existencial (SARACENO, 2001). O trabalho, visto como meio de inserção, pode, ao invés disso, promover um processo de articulaçấo do campo dos interesses, das necessidades e dos desejos (SILVA; OLIVEIRA; BERTANI, 2007).

Dada a situação de intensa exclusão social a que as pessoas com transtorno mental estáo expostos, somada ao fato de no contexto capitalista não haver condiçôes favoráveis para a inclusão dessa população, a autogestáo apresenta-se como um dos caminhos para inserção laboral desses indivíduos (SILVA; OLIVEIRA; BERTANI, 2007). Por se apresentar de forma tão inclusiva, por permitir que o trabalhador manifeste sua opinião e por compreender as limitaçôes deles, muitos trabalhadores têm feito a opção pela Economia Solidária que possibilita, por exemplo, aos usuários de serviços de saúde mental tornarem-se trabalhadores solidários e conseguirem não só apoio para a entrada no mundo social e comunitário como também sua participação nas decisóes e na gestão de sua própria vida (SILVA; OLIVEIRA; BERTANI, 2007). Economia Solidária e saúde mental tiveram sua parceria firmada definitivamente no Brasil em 2005, já que nesse ano a Área Técnica de Saúde Mental do Ministério da Saúde e a Secretaria Nacional de Economia Solidária do Ministério do Trabalho e Emprego regulamentaram a uniáo pela portaria interministerial n. 353, de 7 de março de 2005, com o objetivo de fomentar as experiências de geração de renda na área de saúde mental. Hoje, a inclusão no trabalho por meio da Economia Solidária faz parte da Política Nacional de Saúde Mental.

$\mathrm{Na}$ Economia Solidária é primordial a promoção das relações de solidariedade, as trocas durante o trabalho e o trabalho coletivo e esses fatores dáo significado ao trabalho realizado. A vinculação desses princípios com o tema saúde mental traz, por sua vez, o desafio de definir formas de os trabalhadores realizarem seu trabalho, as açôes suscetíveis de modificarem o seu destino de sofrimento e como esse sofrimento pode ser transformado em criatividade, favorecendo a saúde (SILVA; OLIVEIRA; BERTANI, 2007).
Já é possível identificar, na realidade brasileira, alguns empreendimentos econômicos solidários nos quais a presença de usuários de serviços de saúde mental é constante e até mesmo majoritária. Porém algumas dificuldades ainda são encontradas: de acordo com Martins (2008) a maior dificuldade encontrada pelas experiências se localiza na fase de formação dos empreendimentos e, em seguida, na sua emancipação dos serviços de saúde mental. $\mathrm{Na}$ tentativa de sanar essa dificuldade, as incubadoras tecnológicas de cooperativas populares (ITCPs), as delegacias regionais do trabalho (DRTs) e os fóruns de Economia Solidária têm se destacado no apoio aos grupos para que se tornem empreendimentos autogestionários (MARTINS, 2008).

O Núcleo Multidisciplinar e Integrado de Estudo, Formação e Intervenção em Economia Solidária da Universidade Federal de São Carlos (NuMI-EcoSol/ UFSCar) está atuando nesse sentido. Desde 2007 vem executando um projeto na perspectiva do desenvolvimento territorial e elegeu como alvo de suas açôes dois bairros periféricos da cidade de São Carlos que constituem bolsôes de pobreza na cidade. Esse projeto tem como um dos objetivos a inclusão social de usuários de serviços de saúde mental residentes no território alvo por meio do trabalho em empreendimentos econômicos solidários.

Em 2008, uma proposta surgiu com o objetivo de inserir usuários de serviços de saúde mental moradores do território alvo em empreendimentos econômicos solidários já existentes na região de São Carlos, mas muitas dificuldades foram encontradas, como falta de adesão por parte dos usuários dos serviços de saúde mental, dificuldade por parte da equipe em inseri-los nos empreendimentos econômicos solidários, dentre outras.

Buscando vias que facilitassem essa proposta, em 2010 foi preparado um programa de orientação profissional para que os usuários de saúde mental elaborassem um projeto de vida, recebessem formação em Economia Solidária e, no final do processo, mais cientes de suas perspectivas futuras, pudessem escolher ingressar em um Empreendimento Econômico Solidário. O programa foi realizado durante 15 encontros, com uma hora de duração cada. Os participantes do programa foram apresentados aos princípios da Economia Solidária e aos Empreendimentos econômicos solidários existentes em São Carlos. Além disso, foram submetidos a 15 técnicas de orientação profissional que tinham como objetivo estimular o autoconhecimento e a capacidade de fazer escolhas.

A orientação profissional para pessoas com transtorno mental, segundo Ribeiro (2004), busca 
criar estratégias promotoras de autoconhecimento e autonomia por meio da realização de projetos ocupacionais - projetos que gradativamente reabilitariam a "pessoa psicótica" a pensar na construção do mundo pela via do trabalho, favorecendo as relaçôes sociais, reafirmando sua identidade profissional e reativando o desenvolvimento de sua carreira. Esse tipo de orientação deve considerar também as próprias limitaçôes impostas pela patologia, pois elas se tornam determinantes no processo de escolha profissional. $\mathrm{O}$ apoio familiar para a concretizaçáo da escolha profissional torna-se imprescindível para que as limitaçôes sejam superadas até que o sujeito conquiste maior autonomia. O diálogo com os profissionais da rede de saúde também é uma ação imperativa para um programa de orientaçáo profissional, pois o acompanhamento clínico dos usuários, bem como a troca de informaçôes entre os profissionais de saúde e a equipe do projeto de inserção dos usuários na realização das oficinas de orientação profissional, é parte fundamental para a adequada realização dos trabalhos (RIBEIRO, 2004).

Esse autor, ao definir um programa de orientação profissional voltado para usuários de serviços de saúde mental, afirma que esse procedimento pode se tornar uma possibilidade de o sujeito transitar de um espaço de doença e tratamento institucional para um espaço de construção de saúde. Além disso, ele auxilia no processo de tomada de decisão e se torna uma importante ferramenta facilitadora da inserção laboral dessa população.

A literatura pouco apresenta sobre a eficácia e a adequação dos programas elaborados para apoiar as pessoas nas questóes relativas ao emprego e à carreira profissional, assim como sobre orientação profissional para usuários dos serviços de saúde mental. Dessa forma, surgem questóes referentes ao impacto que os programas e serviços de orientação profissional ou desenvolvimento de carreira têm, em longo prazo, na vida de jovens e adultos usuários e não usuários de serviços de saúde mental (FRENCH; HIEBERT; BEZANZON, 1994 apud ALMEIDA, 2006).

Desse modo, analisar criticamente os serviços prestados, do ponto de vista dos ex-participantes de programas de orientação profissional, permite aferir a adequação dos recursos disponíveis para o atendimento às reais necessidades do sujeito. O presente estudo se propôs a contribuir nesse sentido, investigando o potencial de um programa de orientação profissional como estratégia para a inserção de usuários de serviços de saúde mental em empreendimentos econômicos solidários, sendo que seus objetivos específicos foram investigar se a exposição de usuários de serviços de saúde mental a um programa de orientação profissional pode facilitar o processo de inserçáo laboral desses indivíduos em empreendimentos econômicos solidários e quais atividades presentes nesse programa puderam facilitar esse tipo de inserção.

\section{Método}

O presente estudo se deu com base no exame de um programa de orientaçáo profissional realizado em 2010 no qual um homem e uma mulher concluíram o programa todo e foram inseridos em um empreendimento econômico solidário.

O empreendimento econômico solidário no qual houve a inserção de usuários de serviços de saúde mental formou-se em março de 2009 e desde então vem desenvolvendo semanalmente práticas de produção agroecológica de hortaliças para o consumo das famílias dos participantes. O número de membros do empreendimento variou muito desde sua formação - no ano de 2010 (ano no qual o programa de orientaçáo profissional e a inserção dos usuários ocorreram) o grupo contou com cerca de seis membros, sendo que dois desses membros eram os usuários de serviços de saúde mental.

Além dos dois participantes do grupo de orientação realizado em 2010, foram participantes deste estudo também dois membros da horta comunitária, colegas de trabalho dos usuários de serviços de saúde mental, e o técnico executivo de nível superior responsável pelas atividades operacionais de incubação do empreendimento, como membro da equipe de uma incubadora universitária de empreendimentos solidários a cujo projeto o empreendimento estava vinculado. Uma descrição dos participantes se pode ser vista na Tabela 1.

Foram utilizadas como fontes documentais, ainda, as atas de todos os encontros realizados no programa de orientação profissional para usuários de serviços de saúde mental do ano de 2010, para caracterizar como esse programa foi desenvolvido e possibilitar a identificação de aspectos do programa potencial ou comprovadamente relacionados à ocorrência de inserção dos participantes nos empreendimentos e as suas características.

Neste estudo foi adotada a metodologia de pesquisa qualitativa como abordagem de investigação científica por meio da qual é possível uma maior apreensão e aprofundamento dos fenômenos sociais estudados (MINAYO, 2000), nesse sentido a mais adequada para o alcance dos objetivos traçados. 
Tabela 1. Identificação dos participantes.

\begin{tabular}{|c|c|c|c|c|c|c|}
\hline Participante & Sexo & Idade & Escolaridade & Estado civil & $\begin{array}{l}\text { Envolvimento com } \\
\text { Economia Solidária }\end{array}$ & Profissão atual \\
\hline S1 FE & M & 27 & Superior completo & Solteiro & $\begin{array}{l}\text { Atua em pesquisa na } \\
\text { área desde } 2009\end{array}$ & $\begin{array}{c}\text { Técnico executivo } \\
\text { da Horta } \\
\text { Comunitária de } \\
\text { São Carlos }\end{array}$ \\
\hline S2 LE & $\mathrm{F}$ & 57 & $\begin{array}{l}\text { Ensino médio } \\
\text { completo }\end{array}$ & Divorciada & $\begin{array}{l}\text { Atuação junto à horta } \\
\text { desde } 2009\end{array}$ & Cooperada \\
\hline S3 MI & M & 60 & $\begin{array}{l}\text { Ensino fundamental } \\
\text { completo }\end{array}$ & Casado & $\begin{array}{l}\text { Atuação junto à horta } \\
\text { desde } 2009\end{array}$ & Cooperado \\
\hline S4 MA & F & 56 & $\begin{array}{l}\text { Ensino fundamental } \\
\text { completo }\end{array}$ & Solteira & $\begin{array}{l}\text { Usuária dos serviços } \\
\text { de saúde mental } \\
\text { incluída na horta em } \\
2010\end{array}$ & Do lar \\
\hline S5 EV & M & 50 & $\begin{array}{l}\text { Ensino superior } \\
\text { completo }\end{array}$ & Casado & $\begin{array}{l}\text { Usuário dos serviços } \\
\text { de saúde mental } \\
\text { incluído na horta em } \\
2010\end{array}$ & $\begin{array}{l}\text { Operário } \\
\text { (afastado do } \\
\text { trabalho para } \\
\text { tratamento) }\end{array}$ \\
\hline
\end{tabular}

Para a coleta de dados, primeiramente o projeto foi submetido ao Comitê de Ética em Pesquisa em Seres Humanos da UFSCar, tendo sido aprovado sob o parecer n. 219/2012 e, uma vez aprovado, foi iniciada a coleta de dados. Para a localizaçáo dos participantes foram realizados contatos com o Núcleo Multidisciplinar e Integrado de Estudos, Formação e Intervenção em Economia Solidária (NuMI-EcoSol), sucessor da Incubadora Regional de Cooperativas Populares da Universidade Federal de São Carlos (INCOOP/UFSCar), para que fossem indicados os contatos das coordenaçôes do programa de orientação profissional realizado em 2010 e do técnico executivo da Horta Comunitária do Jardim Gonzaga.

Após os objetivos da pesquisa terem sido esclarecidos, foi solicitado ao técnico executivo a participaçáo dele na pesquisa e o contado de mais dois cooperados, que ele poderia indicar livremente. Para a coordenação do programa de orientação profissional foi solicitado o contado dos dois participantes que concluíram todo o programa $\mathrm{e} o$ acesso às atas que continham os registros dos encontros realizados durante o programa de orientação profissional. Feito entấo o contato com os demais participantes e esclarecidas as dúvidas, foi solicitado para aqueles que aceitaram participar $\mathrm{da}$ pesquisa que assinassem o Termo de Consentimento Livre e Esclarecido - TCLE. Os dados foram coletados a partir da utilização da técnica de entrevista semiestruturada.

Nessa situação, também a aplicação da entrevista ocorreu em local e horário previamente combinados entre pesquisadora e os participantes da pesquisa, tendo sido utilizados um protocolo de informaçóes pessoais e profissionais e um roteiro que previa a obtenção de informações sobre a influência do programa de orientação profissional na entrada e permanência dos usuários de serviços de saúde mental no empreendimento econômico solidário.

As entrevistas foram gravadas na íntegra em gravador digital e, assim que realizadas, transferidas do gravador digital para o computador e transcritas. Para a ordenaçấo dos dados obtidos por meio das entrevistas, elas foram transcritas em sua íntegra e foram feitas leituras exaustivas dos textos, buscando-se uma apreensão global. Em seguida foi feita a identificaçáo das características do programa de orientação profissional que possivelmente influenciaram na tomada de decisão e efetiva inserção desses usuários de serviços de saúde mental no empreendimento econômico solidário, com a localização de palavras e expressóes-chave. $\mathrm{Na}$ sequência foi realizada a categorizaçáo dos temas e elaborada uma matriz de categorias analíticas, em termos de variáveis e valores de variáveis relacionadas positiva ou negativamente com os resultados de interesse (inserçáo dos participantes em empreendimentos solidários).

Para análise das atas dos encontros, o seu conteúdo foi lido sequencialmente e em ordem cronológica e aquelas informaçóes que pareceram indicar componentes provenientes do programa de orientação profissional que possivelmente vieram a contribuir com a inserção foram anotadas em um caderno.

Ao final do processo, uma comparaçáo dos dados obtidos por meio das entrevistas com todos 
os participantes deste estudo foi feita, entre elas e delas com as informaçóes referentes ao processo de orientação profissional, para identificar se haviam indicativos de relaçôes entre características desse processo e facilitação do processo de inserção das pessoas que passaram por ele em empreendimentos econômicos solidários e de que tipo eram elas.

\section{Resultados}

Os resultados convergem na direção da orientação profissional como facilitadora da inserção dos usuários de serviços de saúde mental no empreendimento econômico solidário, na medida em que as técnicas utilizadas demostraram gerar sentimento de segurança, ajudaram na identificação de interesses e mostraram novas possibilidades de trabalho. As fontes de informação consultadas ressaltam principalmente a promoção da segurança e da identificação com o trabalho na terra; além disso, os resultados demonstram que ao passarem pelo programa de orientação profissional os usuários de saúde mental puderam conhecer e vivenciar uma realidade que até entáo era percebida como possível, ou seja, eles perceberam que eram aptos a exercer um tipo de trabalho, passando, entáo, de doentes e incapacitados à condição de trabalhadores.

$\mathrm{Na}$ Figura 1 podem ser vistos os resultados correspondentes à opiniâo do técnico executivo e dos dois cooperados entrevistados sobre o desempenho dos participantes do programa de orientação profissional no empreendimento econômico solidário.

Os dados apresentados na Figura 1 indicam que, de acordo com os entrevistados, os usuários de serviços de saúde mental que passaram pelo programa de orientação profissional receberam uma avaliação positiva de seus colegas de trabalho.
Apenas um cooperado declarou que eles estavam menos preparados que os demais para o trabalho na horta; segundo ele, os participantes do programa não sabiam como lidar com a terra, mas em todos os outros fatores eram iguais a qualquer outro cooperado.

Dados obtidos quanto ao nível de informação desses entrevistados em relação ao programa de orientação profissional indicaram que tanto para os outros cooperados quanto para o técnico executivo ele era muito baixo, já que todos consideraram ter poucas informaçôes a respeito. Todavia, apesar de não terem muitas informaçóes, um cooperado declarou que na opiniáo dele a orientação profissional contribuiu consideravelmente para entrada e permanência dos participantes do programa no empreendimento. $\mathrm{O}$ outro cooperado e o técnico executivo consideraram que contribuiu muito e todos eles consideraram que o programa de orientaçáo profissional é uma boa estratégia para inserção de usuários de serviços de saúde mental em empreendimentos econômicos solidários.

O cooperado S3MI não conseguiu explicar por que motivos acredita que a orientação profissional é uma boa estratégia de inserção, mas S2LE declarou acreditar que o programa de orientação profissional facilita a inserção, pois ajuda as pessoas a reconhecerem o que gostam de fazer e aprender do que são capazes; dessa forma ficam mais motivadas a iniciar uma nova atividade de trabalho. Depois de passar pelo programa, segundo ela,

[...] a pessoa acaba reconhecendo o que gosta e escolhe a partir daí. Assim dá certo, afinal a pessoa já sabe o que vai gostar antes mesmo de começar as atividades.

O técnico executivo, por sua vez, relatou que o programa faz com que as pessoas cheguem mais motivadas e compreendam que fizeram uma boa escolha. Em suas próprias palavras:

Igual aos outros $\square$ Mais que os outros $\square$ Menos que os outros

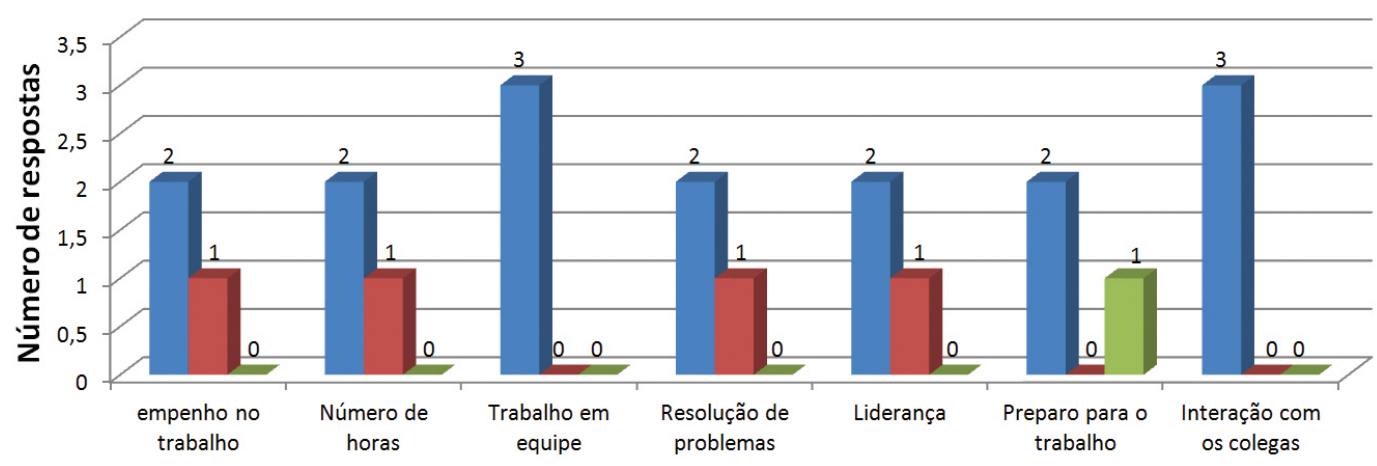

Figura 1. Distribuição das respostas das outras pessoas entrevistadas em relação ao desempenho dos participantes do programa de orientação profissional em comparação com o de outros cooperados. 
A pessoa se permite chegar acreditando que aquilo vai dar certo. Ela não chega lá pensando que talvez náo dê certo, ela chega acreditando naquilo lá. Comparando essas pessoas que passaram pela orientaçâo profissional e as que não passaram, dá a impressão que as que passaram acreditam mais na participaçáo no empreendimento.

Em relação à opinião dos usuários de serviços de saúde mental sobre as atividades do programa de orientação profissional, os dados indicaram que mesmo tendo se passado aproximadamente dois anos da realização do programa de orientação profissional, os participantes dele demonstravam lembrarem-se das atividades realizadas e conseguiam indicar aspectos das atividades que trouxeram melhoras tanto no contexto pessoal e familiar como no contexto de trabalho.

O participante S5EV declarou que gostava das reuniōes (referindo-se aos encontros do programa) porque havia diálogo e entendimento e isso o fazia sentir-se seguro para ousar e tomar decisóes. Segundo ele, ainda, sempre que participava se sentia mais feliz e voltava para casa mais tranquilo e reflexivo.

S4MA lembrou-se de duas das técnicas utilizadas no programa de orientaçáo profissional: a técnica do "dia ideal" e a da "nave de Noé". Pode-se considerar que ambas as técnicas proporcionam ao participante um alto poder de escolha, e revelam possíveis interesses. Ela relatou que gostou muito dessas técnicas porque conseguiu imaginar um mundo no qual suas escolhas fossem levadas em consideração. Além disso, ela contou que gostava muito dos encontros e que se sentia mais capacitada e segura:

Eu me sentia a dona do mundo. Sentia que podia ser e fazer qualquer coisa.

Foi pedido a eles que atribuíssem notas de zero a dez a cada uma das atividades realizadas como parte do processo de orientação profissional. As atividades que receberam maior pontuação, em ambos os casos estavam relacionadas com aspectos da vivência pessoal, ou seja, atividades que remetiam à história de vida do indivíduo como, por exemplo, a técnica de construção da linha da vida. Essa técnica consiste em traçar uma linha reta, na qual cada participante deve incluir em ordem cronológica os acontecimentos que consideraram importantes em sua vida. Sendo assim, é possível perceber quais episódios do passado foram relevantes e os participantes podem compreender que acontecimentos do passado acabam por definir o presente, no qual se sentem muitas vezes insatisfeitos.

Embora as pessoas participantes não tenham conseguido dizer claramente por que gostaram mais de uma ou da outra, conseguiram reconhecer a importância das atividades em sua vida e relataram terem se sentido bem realizando as tarefas. Além disso, reconheceram que, ao passarem pelo programa, houve maior motivação para buscarem um tipo de trabalho e pensarem em perspectivas futuras. Isso fica claramente evidenciado na fala da usuária S4MA ao se referir ao programa:

Foi muito importante para mim, porque eu estava
com uma depressão e fazendo as atividades eu me
sentia importante... Parecia que eu era valorizada,
que estava sendo útil para alguma coisa. Naquela
época eu estava muito ruim mesmo. Sabe quando
a pessoa está sem rumo? Sem perspectiva de vida?
Aí, depois de passar pelo grupo foi diferente. Eu
encontrei uma funçấo. Foi muito bom para mim!

Em termos de mudança de vida após a participação no programa, as respostas dos participantes indicam terem notado também melhoras na capacidade de tomar decisóes, aumento da autoestima, aumento do sentimento de segurança, melhoras na resolução de conflitos pessoais, familiares e profissionais e aumento das habilidades de interaçáo social e de liderança.

S5EV relatou que as atividades ajudaram a tomar decisões junto à esposa e aos filhos e, segundo ele, a decisão de entrar na horta foi a melhor de suas escolhas. S4MA, por sua vez, disse acreditar que o programa a ajudou não só a tomar decisóes como a assumir responsabilidades. Em sua própria fala:
Eu mudei até em casa... eu não levantava... só levantava para comer e voltava a dormir... eu não fazia nada. Ai, depois eu comecei a cuidar das tarefas domésticas em casa, a trabalhar na horta e assumir responsabilidades com eles aqui. $O$ ano passou e eu nem percebi... Ajudou-me bastante. Eu não conseguia fazer nada, depois eu até ajudava... Até trabalhei.

Sobre a relação que tinham com a equipe que conduzia a aplicação das técnicas de orientação profissional, ambos destacaram que se sentiam acolhidos e que se sentiam mais seguros para tentarem novas possibilidades:

Eu me sentia acolhido, aprendi a interagir e passei a me sentir mais seguro. (S5EV).

Me sentia feliz na companhia das pessoas, me sentia segura. (S4MA).

O participante S5EV reconheceu que o programa de orientação profissional ajudou-o a lidar com conflitos de ordem pessoal e familiar, mas afirmou acreditar que, para trabalhar todos os dias, precisaria de mais um tempo de preparação. Além disso, ele 
disse que após passar pelo programa ele se envolveu mais em práticas de liderança; em suas palavras:

Eu tive mais noçâo de liderança, compromisso e responsabilidades e comecei a me engajar mais nas atividades.

Já S4MA considerou que o programa fez muitas mudanças em sua vida e a fez sentir-se apta para entrar em um empreendimento econômico solidário:

Mudou tudo. Mudou minha cabeça, eu fiquei mais disposta, perdi um pouco da timidez, eu tinha vergonha antes de conversar com as pessoas, depois que comecei a participar mudou... Foi muito importante para mim, me sentia segura e capaz de participar da horta.

Os dois usuários entrevistados relataram acreditar que o programa de orientação profissional facilitou a entrada e permanência deles no empreendimento econômico solidário. Segundo S5EV o programa ajudou-o a descobrir do que gostava, a se conhecer e a ter coragem para entrar e, segundo S4MA, o programa possibilitou que ela se sentisse mais segura e apta a participar de um empreendimento, pois antes ela achava que não era capaz disso. Segundo ela:

Eu achava que era um bicho-de-sete-cabeças trabalhar em um empreendimento, depois eu fiquei mais segura... Comecei a pensar mais sobre mim mesma e sobre o que eu queria, ai quando eu conheci a horta eu achei que era isso que en queria para mim.

Quando questionados sobre se houve algum momento do programa de orientação profissional no qual eles decidiram entrar no empreendimento, S5EV respondeu que náo houve um momento específico, mas que com o passar dos encontros foi sentindo que poderia ser uma escolha interessante para ele. S4MA, por sua vez, declarou que começou a se sentir mais apta a trabalhar e que, ao ver o filme das cooperativas, que foi apresentado durante a etapa de formaçáo em Economia Solidária, ela teve vontade de participar:

Eu vi os filmes das cooperativas... Eu vi as pessoas trabalhando... Comecei a me conhecer melhor, a pensar em fazer alguma atividade. Eu achei que se eu entrasse no empreendimento ia ser igual aos filmes que eu vi, aí eu decidi entrar.

De acordo com os relatos dos participantes do programa de orientaçáo profissional inseridos no empreendimento, dentre os temas abordados no programa, os mais importantes para ambos foram esclarecimento de interesses e reflexão sobre o futuro.
$\mathrm{Na}$ análise das atas foi possível encontrar principalmente falas sobre a mudança que os participantes do programa foram manifestando ao longo dos encontros e sobre as impressóes da equipe frente ao que as técnicas apresentavam. No terceiro encontro, por exemplo, o texto sugere que os participantes demonstravam prazer na atividade e habilidades relevantes para atividades laborais:

Quando questionados sobre as atividades e a participação no grupo E disse que estava sendo bom porque se desligava de outras coisas."; e "Os participantes mostraram-se envolvidos e concentrados quanto à participação e realização das dinâmicas.

No quarto encontro do programa, um dos participantes já demonstrava interesse em ingressar em um empreendimento. $\mathrm{Na}$ ata desse encontro, a seguinte frase foi escrita:

Nesse encontro tornaram-se mais claros para a equipe os interesses de cada participante do grupo, devido às técnicas de autoconhecimento $e$ apresentação realizadas nos encontros anteriores. Ao final desse encontro. um dos participantes demonstrou interesse em ingressar em um empreendimento.

No quinto encontro, ao combinar com o participante que demonstrou interesse em conhecer a horta, o dia e o horário da visita, outra participante manifestou desejo de ir junto:

Quando combinávamos com $E$ a visita à horta, $M$ manifestou interesse também e então ficou decidido que na terça [25/5/10] [E e L] acompanharäo a visita de $M e$ E à horta.

No sexto encontro, as técnicas realizadas tinham como objetivo questionar sobre a escolha da profissão e sobre as possibilidades futuras de trabalho; segundo a ata, a utilização das técnicas mostrou que existiam muitas alternativas e os participantes puderam perceber que possuíam possibilidades de escolha, sendo possível, então, escolher.

Durante a formação em Economia Solidária, a análise da ata demonstra que os participantes gostaram de conhecer uma nova perspectiva de trabalho, sendo que um deles, que já estava inserido, contou sobre sua experiência: " $E V$ remeteu o assunto à horta e disse que é uma nova perspectiva de trabalho para ele, e que está gostando de conhecer essa forma diferente de renda." (encontro 11).

Nas atas também foi possível encontrar o relato da equipe sobre os efeitos do programa: 
O grupo parece funcionar muito bem, têm sido muito agradáveis os momentos de descontração, os usuários parecem interagir de forma saudável, por vezes todos nós reservamos um momento para "conversas paralelas" o que demonstra um bem-estar geral de estarmos ali. Acho que conseguimos uma coesão grupal e que este grupo tem funcionado através da presença e participação de todos. (encontro 12).

EV exibe claramente uma mudança de comportamento, parece muito mais envolvido, interage com os outros usuários e conosco, fala da horta com bastante ânimo e empenho. Suponho que ele é o que reflete mais nitidamente os efeitos positivos do programa. (encontro 13).

Falas e reflexóes dos próprios participantes do programa também foram observadas nas atas:

EV comentou inúmeras vezes que está feliz na horta, o que está em consonância com os resultados observados na OP e disse que reconhecer seu gosto pela terra foi muito importante na escolha de ingressar na horta. (encontro14).

MA comentou que se sente feliz no empreendimento e que pretende continuar, relata que o processo de OP a ajudou a pensar sobre si mesma e durante a devolutiva levantou muitos problemas de ordem pessoal. (encontro14).

No último encontro, o texto na ata demonstra que os objetivos pensados para o programa de orientaçáo profissional foram alcançados:

Foi um momento marcado por despedidas e acordos, os usuários que foram inseridos se sentem preparados para o trabalho e continuarão a ser acompanhados em seu local de trabalho, já os demais se despediram e refletiram um pouco sobre os momentos que passaram juntos no grupo. (encontro 15).

\section{Discussão}

Embora a maioria dos usuários de serviços de saúde metal não sejam mais enclausurados em instituiçôes psiquiátricas, acabam sendo aprisionados em suas próprias casas, não encontrando muitas alternativas para manifestarem-se como seres sociais. Aposentar as pessoas com transtorno mental por invalidez é a alternativa escolhida pela sociedade para lidar com seus desajustados, mas não tem a ver com o fato de a pessoa com transtorno mental não ser capaz de exercer um trabalho. Para Saraceno (2001, p. 32), a aposentadoria seria "[...] a resposta que a organização social dá ao sujeito com desabilitação [...]", entendida como "[...] redução das performances cognitivas e sociais."

Sendo assim, usuários de serviços de saúde mental acabam se acostumando a serem excluídos das decisões em seu ciclo social, acabam por acreditar que não possuem poder de escolha e se resignam a seguir aquilo que outros decidiram por eles. $\mathrm{O}$ objetivo do programa de orientaçáo profissional investigado era não apenas ajudar os usuários de serviços de saúde mental a escolher uma profissão, mas também ajudá-los a desenvolver a capacidade de fazer escolhas, fortalecer competências que os ajudassem a exercer uma atividade de trabalho e a criar um projeto de vida, entendido como qualquer açáo que envolvesse a participação da pessoa na construção do seu futuro: um projeto individualizado de existência, que não se reduz à simples possibilidade de fazer escolhas (FONSECA, 1994). Para Ribeiro (2004), um programa de orientaçáo profissional para usuários de serviços de saúde mental deve levar em conta náo somente a elaboraçáo de um projeto, mas também a realização de um plano de ação que considere a lógica das possibilidades e probabilidades da população alvo, mas também a lógica das condiçóes ambientais, que podem ou não estimular tal projeto.

O programa utilizado e avaliado considerou as variáveis indicadas investigando as potencialidades e limitaçóes de cada participante, como se relacionavam com seus pares, quais oportunidades de emprego eram oferecidas para eles na cidade e, dentre elas, quais eram mais viáveis para a efetiva inserção. Como apresentado anteriormente, os resultados mostraram que houve uma boa aceitação da participação dos usuários no empreendimento em que foram inseridos e que eles se adaptaram às atividades de forma satisfatória. Além disso, tanto os cooperados quanto o técnico executivo entrevistado relataram acreditar que a orientaçáo profissional tenha sido uma boa estratégia para inserção no empreendimento - mesmo considerando as limitaçóes impostas a essa possibilidade de avaliação, pela forma como se deu a intervenção.

A motivação para o trabalho e a certeza de ter feito uma escolha adequada foram citadas como diferenciais dos participantes do programa de orientação profissional e dos outros cooperados; esse fato pode estar fortemente relacionado com o processo de orientaçáo profissional que, como destaca Coutinho (1993), gera esclarecimento sobre o tipo de trabalho a ser realizado, levando ao autoconhecimento, aliado à reflexão sobre a 
função de cada indivíduo no mundo de trabalho, a compreensão de desejos e limitações.

Nesse sentindo, os dados obtidos indicam que o programa de orientação profissional foi uma importante ferramenta para que os participantes pudessem aprender a escolher levando em consideração as possibilidades de que dispunham. É possível concluir que os principais resultados alcançados estáo relacionados com o aumento da autoestima, da autonomia e do poder de escolha, alcançando-se assim os objetivos propostos.

Buscar autonomia, aprender a escolher e ingressar no mundo do trabalho não são tarefas fácies para os usuários de serviços de saúde mental. Para Ribeiro (2004, p. 107), a orientação profissional:

[...] seria a grande chance de uma parte das "pessoas psicóticas" arriscarem novas modalidades de projeto. Digo uma parte pois muitos ficarão mais perdidos e impossibilitados do que estavam diante de uma fragilidade da referência simbólica vigente que, se impossibilitava uma autonomia, possibilitava ser dependente dela, e outros tantos continuaráo estabilizados nas saídas que o mundo moderno propóe como, por exemplo, a aposentadoria por invalidez e a incorporação da identidade de doente mental.

Para o autor, embora a orientação profissional para usuários de saúde mental seja um importante recurso reabilitativo, ela não abrange a todos. Os usuários de serviços de saúde mental que passaram por longos períodos de internação ou que não estáo recebendo medicação de forma correta em geral não apresentam condiçóes de acompanhar e responder às técnicas e frequentemente necessitam receber tratamento psiquiátrico e terapêutico adequado antes de participar de um programa de orientação profissional.

O quadro clínico dos participantes que conseguiram se inserir, no caso deste estudo, era estável e os prognósticos eram positivos; esses fatos podem ter levado a um maior aproveitamento das técnicas de orientação profissional e à inserção no empreendimento. Outro aspecto complicador para atingir êxito em programas de orientação profissional para usuários de serviços de saúde mental é que muitas vezes os participantes dependem da disposição da família para levá-los aos encontros e nem sempre isso é possível. Sendo assim, muitos usuários de serviços de saúde mental acabam por desistir ou nem chegam a tentar participar do programa, já que não têm como chegar até o local dos encontros.
Com a reforma psiquiátrica, as portas dos manicômios foram abertas, os doentes retornaram para suas famílias e desde então as famílias tiveram que aprender a conviver com o portador de transtorno mental. Já não é mais aceitável estigmatizar ou excluir os portadores de transtorno mental, mas também não é desejável reduzir a reforma psiquiátrica à devolução dos portadores de transtorno mental à família, como se essas fossem, indistintamente, capazes de resolver a problemática da vida cotidiana somada às dificuldades criadas pela convivência, pela manutençáo e pelo cuidado com o doente mental (GONÇALVES; SENNA, 2001).

A mudança das diretrizes da assistência em saúde mental, optando pelo atendimento em regime aberto, implica em uma importante mudança da relação do profissional de saúde mental com a família do usuário, importantes parceiras no processo de reabilitação. A falta de orientação às famílias pode fazer com que surjam conflitos e descompassos entre a pessoa com transtorno mental e a dinâmica familiar, com prejuízos para o processo de reabilitação (PEREIRA; PEREIRA JUNIOR, 2003). Dessa forma, a orientação e o preparo da família da pessoa com transtorno mental devem ser considerados também forma favorecedora de reabilitação. Sem o apoio da família, o sucesso de qualquer prática no sentido da reabilitação fica impossibilitado ou muito dificultado.

Os participantes do programa de orientação profissional entrevistados relataram mudanças significativas na relação com seus familiares após a entrada no grupo e disseram que eram apoiados e incentivados por eles a participar. $\mathrm{O}$ apoio da família pode ter sido uma variável significativa para a participaçáo deles no programa e, posteriormente, para entrada no empreendimento.

Machado (1978) acredita que a família deve ser compreendida como uma unidade básica da saúde, em um modelo de intervenção que possibilite resolver os problemas cotidianos, diminuindo o stress e, indiretamente, as recaídas. Na visão da família como a unidade básica é possível considerar que, para cumprir o papel de provedora ela necessita, além dos recursos institucionais, do preparo e do apoio de profissionais (PEREIRA; PEREIRA JUNIOR, 2003). Açóes que forneçam às famílias de usuários de saúde mental capacitação no sentido de ajudá-las a compreender a doença do familiar, suas potencialidades e limitaçóes favorecem também a reinserção do doente na sociedade e, portanto, devem ser motivo de estudo e experimentação por parte dos profissionais da saúde e da educação. 
As técnicas utilizadas no programa de orientação profissional também contribuíram para o alcance de resultados satisfatórios, pelo menos em parte, pela adaptação pela qual passaram para uso com a população alvo; além disso, foram organizadas de forma a gerar mudanças gradativas que levassem ao aumento da autonomia e à melhoria na capacidade de fazer escolhas dos participantes. Ribeiro (2004) afirma que o sucesso de um programa de orientação profissional para usuários de serviços de saúde mental é favorecido pela adaptação das técnicas e do programa como um todo, considerando as próprias limitaçóes impostas pelas patologias presentes, pois assim permitem uma maior participação e envolvimento dos participantes na prática das atividades. Sendo assim, as adaptaçóes realizadas no programa investigado podem ter sido essenciais no processo de decisão dos participantes de entrarem no empreendimento.

Das técnicas realizadas no programa, aquelas relacionadas à história de vida e as que objetivavam criar estratégias que auxiliassem no processo de tomada de decisão foram as de que os participantes mais gostaram. É possível supor que, nesses momentos, eles podiam ser ouvidos e se sentiam valorizados. S4MA relatou se sentir valorizada, útil e capaz de decidir, chegando a dizer que se sentia "a dona do mundo". S5EV, por sua vez, relatou sentir-se acolhido e livre para manifestar opinióes, sentindo que suas escolhas eram respeitadas. As sensaçóes descritas pelos participantes condizem com o que Ribeiro (2004) espera como resultado de um programa de orientação profissional para usuários de serviços de saúde mental. Segundo ele, a orientação profissional oferece ao sujeito a possibilidade de encontrar estratégias que o auxiliem no processo de escolha, visando assim garantir a instrumentação do sujeito para a elaboraçáo de planos profissionais, oferecendo um espaço de mediação que garante minimamente o resgate do vínculo com o social e estimula a conquista da autonomia, na medida que responsabiliza os participantes pelas suas escolhas.

Foi possível perceber também que o vínculo criado entre a equipe e os participantes do programa foi considerado positivo; conforme indicam Soares et al. (2007), a vinculaçáo positiva entre a equipe responsável pela orientaçáo e os orientados contribui para que os participantes se sentissem acolhidos e seguros para expressarem suas opinióes e fazerem suas escolhas. Ribeiro (2004) afirma ainda que um grupo coeso no contexto da orientação profissional funciona como uma microssociedade, representando, dessa forma, a sociedade como um todo. Sendo assim, cada sujeito pode aprender a fazer escolhas dentro de um contexto relacional, possibilitando que esse processo tenha características e formas semelhantes às que podem acontecer em suas relaçóes sociais concretas - com a vantagem de ocorrerem em ambiente mais protegido e controlado, condição importante para proporcionar novas aprendizagens a populaçóes com história de vida pouco favorável nesse tipo de situação.

Além de aprender a escolher, os participantes do programa manifestaram, por meio de suas falas, várias outras mudanças que ocorreram em sua vida após a participação no programa de orientação profissional, sendo as principais o aumento da autoestima, o sentimento de segurança e de sentirem-se capazes. Essas melhorias podem estar relacionadas ao aumento da autonomia proporcionada pela participação no programa e pela entrada em um empreendimento econômico solidário.

S4MA declarou que com o passar dos encontros ela foi se sentindo mais capaz de trabalhar e, ao ver o filme que ilustrava o trabalho em cooperativas, sentiu o desejo de ingressar no empreendimento. Esse desejo pode ter ocorrido pelo fato de que nos filmes apresentados no programa de orientação profissional os princípios da Economia Solidária ficavam bem aparentes. Coutinho et al. (2005) afirmam que a Economia Solidária tem se disseminado cada vez mais entre as camadas da população excluídas do mercado formal de trabalho e sido um importante meio de sobrevivência das pessoas pertencentes a essas camadas. Para Martins (2008), a proposta de inclusão social pelo trabalho por meio da Economia Solidária não é casual. Seus princípios, principalmente a autogestáo, a justiça social, o trabalho coletivo e as relaçôes solidárias propiciam a inserçáo social dos usuários de serviços de saúde mental, além de estimular a tomada de decisóes e a gestáo da própria vida. Para Rotelli (2000), a emancipação e a conquista da autonomia dos usuários de saúde mental estão intimamente relacionadas ao processo de formação ativado pela inserção laboral, ou seja, no momento em que a pessoa está inserida em um contexto de trabalho preocupado com sua formaçáo social, política e cultural, ela se dá conta do mundo ao seu redor, toma consciência de seus desejos e interesses e passa a participar dos momentos de troca de experiências que são muito reduzidos no mundo dos usuários dos serviços de saúde mental.

As falas dos participantes do presente estudo colocam em evidência o caráter emancipatório proporcionado pelo trabalho no contexto da Economia Solidária. Foi possível perceber que ao entrar em contato, por meio do programa de orientação profissional, com os princípios da 
Economia Solidária, os participantes reconheceram ali uma oportunidade de exercer uma atividade produtiva em um ambiente que se importa com o trabalhador e não só com a produção, e que compreende as limitaçóes de cada trabalhador. E, após a inserção deles no empreendimento foi possível perceber que passaram a acreditar que também eram capazes de realizar mudanças em sua própria vida, no contexto familiar e pessoal, conquistando assim maior autonomia.

Dessa forma a criação de políticas públicas que apoiem e incentivem a Economia Solidária se faz extremamente necessária. Lussi (2009) argumenta que a criação e a implementação de políticas públicas que fomentem efetivamente a geração de trabalho e renda são primordiais para criar possibilidades reais de ingresso de pessoas que se encontram em situaçáo de desvantagem social no mundo do trabalho ou de seu retorno a esse mundo. É possível supor então que quanto maior o número de empreendimentos econômicos solidários existentes, e quanto mais variados forem seus ramos de atuação, maiores serão as oportunidades para os usuários de serviços de saúde mental e para toda uma população excluída socialmente.

O presente estudo investigou possíveis relações entre a participação de usuários de serviços de saúde mental em um programa de orientação profissional e a entrada deles em empreendimentos econômicos solidários, bem como sua adaptação a eles, procurando refazer o caminho no sentido inverso por meio de dados, em busca de fatores causais plausíveis. Todavia, o estudo foi realizado dois anos após a execução do programa de orientaçáo profissional, e embora os participantes tenham demonstrado lembrar bem dos momentos vivenciados, muito já podia ter sido esquecido ou ofuscado por novos acontecimentos na vida dessas pessoas. Se esse estudo fosse realizado logo após o término do programa de orientação profissional, mais e melhores dados poderiam ter sido obtidos. Como ressalta Cozby (2003), a latência entre a ocorrência do evento de interesse e a coleta de dados é uma das desvantagens de estudos não experimentais, que utilizam como método a entrevista, pois durante esse tempo de latência os participantes podem náo lembrar ou lembrar com poucos detalhes dos fatos.

Seria interessante que novos estudos com os mesmos objetivos deste fossem realizados. Poderia ser realizado um estudo com menor tempo de latência entre o término do programa de orientação profissional e a coleta de dados, ou ainda um estudo experimental, contendo um grupo controle. $\mathrm{O}$ uso do estudo experimental seria interessante, pois, como argumenta Cozby (2003), por meio desse tipo de estudo é possível um maior controle das variáveis; respostas mais claras e menos ambíguas do que as respostas obtidas em uma pesquisa não experimental podem ser obtidas, em geral; há maior confiança em seus resultados e maior flexibilidade; as variáveis podem ser manipuladas sozinhas ou em conjunto com outras variáveis; além disso, o estudo poderia ser replicado.

Talvez assim fosse possível contemplar aspectos que o presente estudo pôde apenas supor como, por exemplo: se o vínculo construído com a equipe influenciou ou não no processo de orientação profissional; qual a melhor forma de conduzir a aplicação das técnicas de orientação profissional; e quais aspectos de cada técnica aplicada especificamente contribuíram para que escolhessem ingressar em um empreendimento econômico solidário. Estudos nessas temáticas podem contribuir para ampliar a compreensão sobre o processo de orientação profissional como via de inserção laboral para usuários de serviços de saúde mental.

Embora algumas limitaçóes tenham sido encontradas, apontando a necessidade de realizar novos estudos, os dados obtidos na presente pesquisa permitem concluir que a orientação profissional pode atuar como condição facilitadora da inserção dos usuários de serviços de saúde mental em empreendimentos econômicos solidários. As técnicas utilizadas demostraram gerar sentimento de segurança, ajudar na identificação de interesses e no processo de escolha, mostrar novas possibilidades de trabalho e estimular a autonomia. Processos de orientaçáo profissional constituem, assim, uma entre outras possibilidades para facilitar a inclusão laboral dessa população e, assim como as demais, dependem também do empenho de toda uma sociedade que seja capaz de valorizar e respeitar as diferenças.

\section{Referências}

ALMEIDA, F. H. Avaliação de um serviço de orientação profissional: a perspectiva de ex-usuários. Revista Brasileira de Orientação Profissional, São Paulo, v. 7, n. 2, p. 81-102, 2006.

BASAGLIA, F. As instituiçôes da violência. In: BASAGLIA, F. (Coord.). A instituição negada: relato de um hospital psiquiátrico. Tradução Heloisa Jahn. Rio de Janeiro: Ediçõoes Graal, 1985. p. 99-133.

CATÃO, M. F. F. M.; TRINDADE, H. C. M. Trabalho, inserção social e realização profissional. In: ENCONTRO NACIONAL DE ENGENHARIA DE PRODUÇÃO, 18., 1998, Niterói. Anais... Disponível em: <http://www. abepro.org.br/biblioteca/ENEGEP1998_ART351.pdf>. Acesso em: 27 jul. 2011. 
COUTINHO, M. C. Subjetividade e trabalho. In: LUCCHIARI, D. H. P. S. (Org.). Pensando e vivendo a orientação profissional. 5. ed. São Paulo: Summus, 1993. p. 117-122.

COUTINHO, M. C. et al. Novos caminhos, cooperação e solidariedade: a psicologia em empreendimentos solidários. Psicologia \& Sociedade, Belo Horizonte, v. 17 , n. 1, p. 7-13, 2005. http://dx.doi.org/10.1590/ S0102-71822005000100002

COZBY, P. Métodos de investigação em pesquisa comportamental. São Paulo: Atlas, 2003.

FONSECA, A. M. Formação pessoal e social e construção de projectos vocacionais. In: FONSECA, A. M. Personalidade, projectos vocacionais e formação pessoal e social. Porto: Porto, 1994. p. 53-81.

GONÇALVES, A. M.; SENA, R. R. A reforma psiquiátrica no Brasil: contextualização e reflexos sobre o cuidado com o doente mental na família. Revista Latino-Americana de Enfermagem, Ribeirão Preto, v. 9, n. 2, p. 48-55, 2001. http://dx.doi.org/10.1590/S0104-11692001000200007

LUSSI, I. A. O. Trabalho, reabilitação psicossocial e rede social: concepçóes e relaçóes elaboradas por usuários de serviços de saúde mental envolvidos em projetos de inserção laboral. 2009. 169 f. Tese (Doutorado)-Escola de Enfermagem de Ribeirão Preto, Universidade de São Paulo, Ribeirão Preto, 2009.

MACHADO, R. Danação da norma: medicina social e constituição da psiquiatria no Brasil. Rio de Janeiro: Graal, 1978.

MARTINS, R. C. A. Saúde mental e economia solidária: construção democrática e participativa de políticas públicas de inclusão social e econômica. In: CORTEGOSO, A. L.; LUCAS, M. G. (Org.). Psicologia e economia solidária: interfaces e perspectivas. São Paulo: Casa do Psicólogo, 2008. p. $245-262$

MINAYO, M. C. S. O desafio do conhecimento: pesquisa qualitativa em saúde. 7. ed. São Paulo: Hucitec; Rio de Janeiro: Abrasco, 2000.

NASCIMENTO, B. A. Loucura, trabalho e ordem: o uso do trabalho e da ocupação em instituiçóes psiquiátricas. 1991. 150 f. Dissertação (Mestrado em Ciências Sociais)Pontifícia Universidade Católica de São Paulo, São Paulo, 1991. PMCid:PMC269817
PEREIRA, M. A. O.; PEREIRA JUNIOR., A. Transtorno mental: dificuldades enfrentadas pela família. Revista da Escola de Enfermagem da USP, São Paulo, v. 37, n. 4, p. 92-100, 2003. Disponível em: <http://www. scielo.br/scielo.php?script $=$ sci_arttext $\&$ pid $=S 0080$ $62342003000400011 \& \operatorname{lng}=\mathrm{en} \& \mathrm{nrm}=\mathrm{iso}>$. Acesso em: 12 jan. 2013.

PITTA, A. M. F. O que é reabilitação psicossocial no Brasil, hoje? In: PITTA, A. M. F. (Org.). Reabilitação psicossocial no Brasil. São Paulo: Hucitec, 1996. p. 19-26.

RIBEIRO, M. A. Orientação profissional para "pessoas psicóticas": um espaço para o desenvolvimento de estratégias identitárias de transição por meio da construção de projetos. 297 f. Tese (Doutorado em Psicologia)-Instituto de Psicologia, Universidade de São Paulo, São Paulo, 2004.

ROTELLI, F. Ri-abilitare la ri-abilitazione. In: ROTELLI, F. Per la normalità: taccuino di uno psichiatra. Trieste: Edizioni E, 1994. p. 96-110. PMid:7711700

ROTELLI, F. Dall'ergoterapia all'impresa sociale. In: TORRESINI, L. (Org.). Il lavoro rende liberi?: dall'ergoterapia all'istituzione inventata. Roma: Sapere, 2000. p. 178-190.

SARACENO, B. Reabilitação psicossocial: uma estratégia para a passagem do milênio. In: PITTA, A. M. F. (Org.). Reabilitaçâo psicossocial no Brasil. São Paulo: Hucitec, 1996. p. 13-18.

SARACENO, B. Libertando identidades: da reabilitação psicossocial a cidadania possível. 2. ed. Belo Horizonte: Te Corá, 2001. PMCid:PMC80930

SILVA, E. P.; OLIVEIRA; T. M.; BERTANI, I. F. Saúde mental e economia solidária: uma relação em construção. In: ENCONTRO INTERNACIONAL DE ECONOMIA SOLIDÁRIA "O DISCURSO E A PRÁTICA DA ECONOMIA SOLIDÁRIA”, 5., 2007, São Paulo. Resumos... São Paulo: NESOL.

SOARES, D. H. P. et al. Orientação profissional em contexto coletivo: uma experiência em pré-vestibular popular. Psicologia: Ciência e Profissão, Brasília, v. 27, n. 4, p. 746-759, 2007. Disponível em: <http://pepsic. bvsalud.org/scielo.php?script=sci_arttext $\&$ pid $=S 1414$ $98932007001200014 \& \operatorname{lng}=$ pt\&nrm=iso $>$. Acesso em: 27 mar. 2012.

\section{Contribuição dos Autores}

Letícia Gomes da Silva: Contribuiu na concepção do trabalho, elaboração do projeto, coleta e organização dos dados, na sua análise e na elaboração e redação do texto. Ana Lucia Cortegoso: Contribuiu na concepção do trabalho, na análise dos dados e na elaboração e redação do texto. Isabela Aparecida de Oliveira Lussi: Contribuiu na concepção do trabalho e na elaboração e redação do texto.

\section{Notas}

${ }^{1}$ Trabalho oriundo de Pesquisa de Iniciação Científica com financiamento do Programa Institucional de Bolsas de Iniciação Científica (PIBIC). A pesquisa foi submetida e aprovada pelo Comitê de Ética em Pesquisa em Seres Humanos da UFSCar sob o parecer n. 219/2012. Trabalho apresentado sob o título “A práxís da Psicologia Social: Para quê? Para quem?”, no XI Encontro Regional ABRAPSO São Paulo, III Encontro Local de Psicologia Social ABRAPSO Cuesta, XI Encontro Local de Psicologia Social Comunitária ABRAPSO Bauru, realizado entre 21 e 24 de março de 2013. 